\title{
Evaluation of Right Ventricular Dyssynchrony in Patients with Acute Inferior Myocardial Infarction and Its Relation with Mortality
}

\author{
batur gonenc kanar ${ }^{1}$, Kursat Tigen ${ }^{2}$, Murat Sunbul ${ }^{2}$, Altug Cincin ${ }^{3}$, Emre Gurel ${ }^{2}$, Nurten \\ Sayar $^{4}$, Alper Kepez ${ }^{2}$, and Beste Ozben ${ }^{3}$ \\ ${ }^{1}$ Marmara Universitesi Tip Fakultesi \\ ${ }^{2}$ Marmara University School of Medicine \\ ${ }^{3}$ Marmara University Faculty of Medicine \\ ${ }^{4}$ Marmara University
}

June 26, 2020

\begin{abstract}
Purpose: The aim of this study was to evaluate right ventricle (RV) dyssynchrony and its relation with mortality using speckle tracking echocardiography (STE) in patients with acute inferior myocardial infarction (IMI). Methods: One hundred and fiftyeight consecutive patients with acute IMI treated with primary percutaneous coronary intervention and 44 healthy subjects were included. RV myocardial involvement (RVMI) was defined as an elevation greater than $1 \mathrm{~mm}$ in V1 or V4R and/or the presence of a culprit lesion at the proximal portion of the first RV marginal branch after reviewing coronary angiography. Patients were followed for three years to determine the cardiovascular mortality. Results: Overall, 70 patients with IMI had RVMI. IMI patients had significantly higher RV peak systolic longitudinal strain dyssynchrony (PLSSD) index, lower peak longitudinal systolic strain (PLSS), longer time to PLSS and time to PLSS differences compared to healthy controls while the patients with RVMI had significantly worse values compared to patients without RVMI and healthy controls. Twenty-seven patients (17.1\%) died within two years. RVMI was more prevalent in mortality group and they had significantly higher RV PSSD index, whereas they had lower RV free wall PLSS and longer time to PLSS differences. ROC analysis revealed that a RV PLSSD index $>65$ ms predicted mortality with a sensitivity of $88.9 \%$ and specificity of $71.8, \%$ in IMI patients. Conclusions:Intra- and interventricular dyssynhcrony may develop in patients with acute IMI, especially in those with RV involvement, which might have a negative effect on the prognosis of these patients.
\end{abstract}

\section{Hosted file}

manuscript.doc available at https://authorea.com/users/336980/articles/462649-evaluationof-right-ventricular-dyssynchrony-in-patients-with-acute-inferior-myocardial-infarctionand-its-relation-with-mortality

\section{Hosted file}

Table 1-4.docx available at https://authorea.com/users/336980/articles/462649-evaluationof-right-ventricular-dyssynchrony-in-patients-with-acute-inferior-myocardial-infarctionand-its-relation-with-mortality 

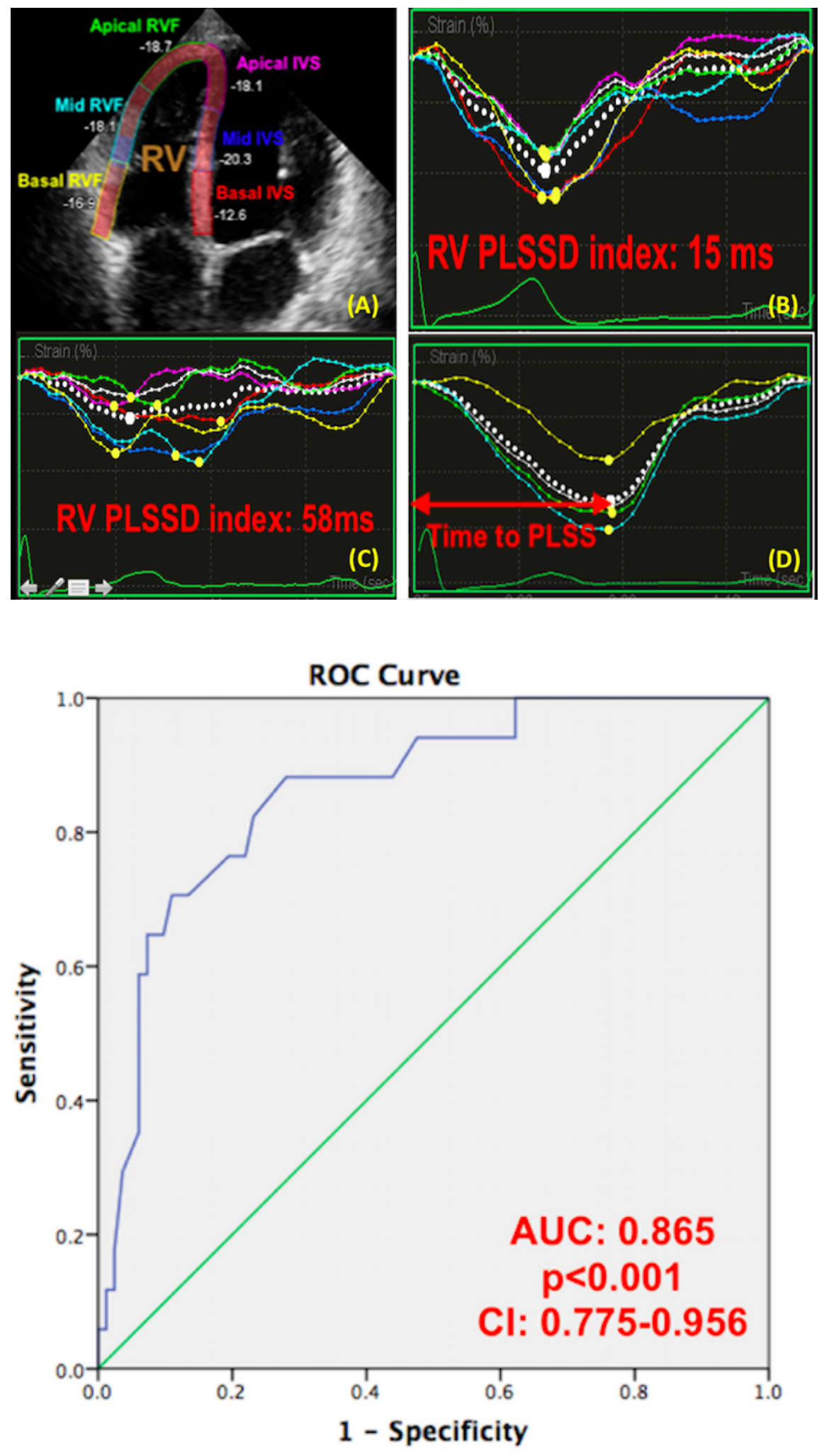


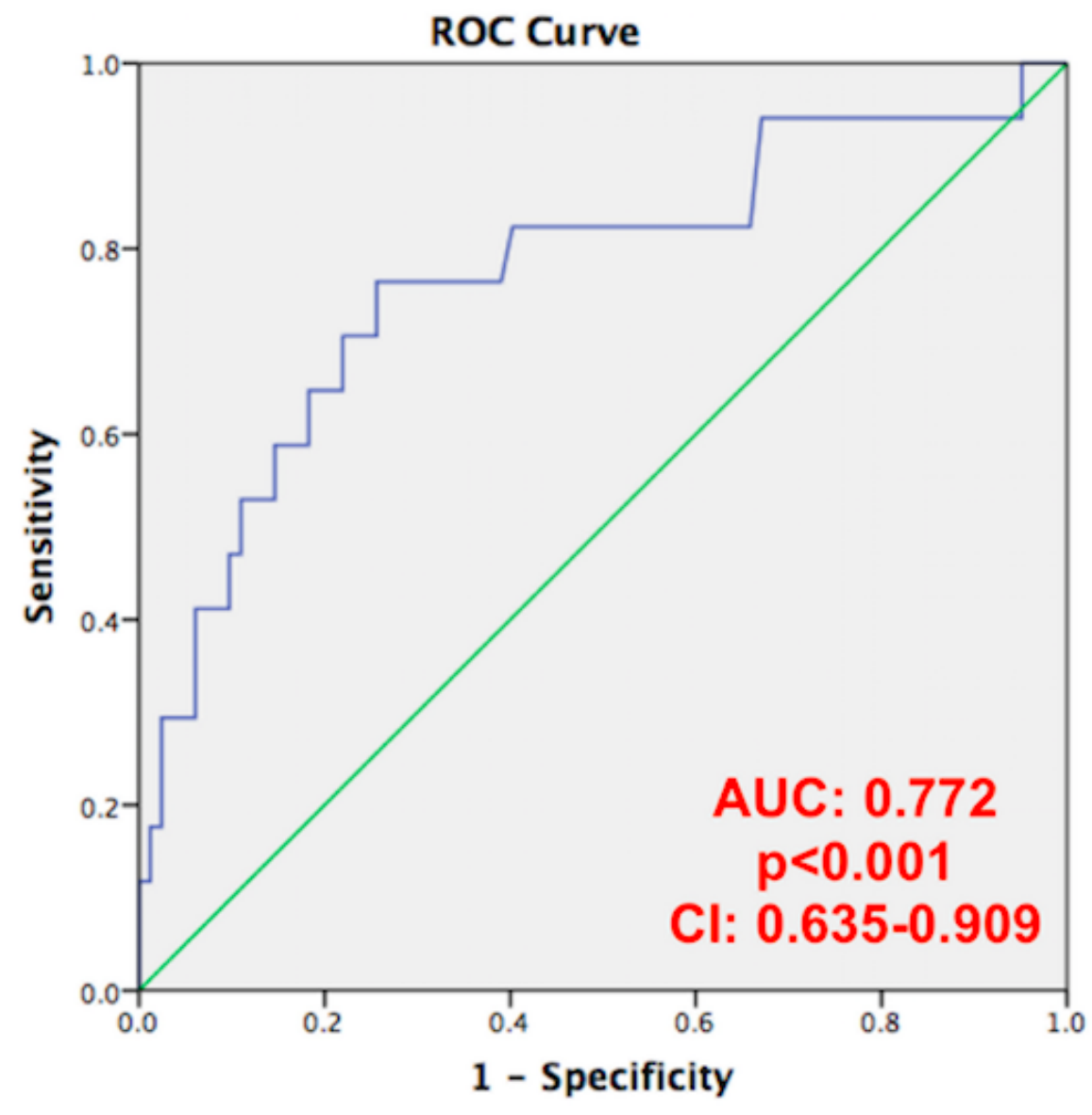

